\title{
Organocatalyzed Synthesis and Degradation of
}

\section{Functionalized Poly(4-allyloxymethyl- $\beta$ -}

\section{propiolactone)s}

Yeji Yu, ${ }^{a}$ Minseong Kim, ${ }^{a, b}$ Gue Seon Lee, ${ }^{c}$ Hyo Won Lee, ${ }^{c}$ Jeung Gon Kim, ${ }^{c}$ and Byeong-Su

$$
\operatorname{Kim} * a
$$

aDepartment of Chemistry, Yonsei University, Seoul 03722, Republic of Korea

${ }^{b}$ Department of Chemistry, Ulsan National Institute of Science and Technology (UNIST),

Ulsan 44919, Republic of Korea

cDepartment of Chemistry and Research Institute of Physics and Chemistry, Jeonbuk

National University, Jeonju 54896, Republic of Korea

E-mail: bskim19@yonsei.ac.kr 


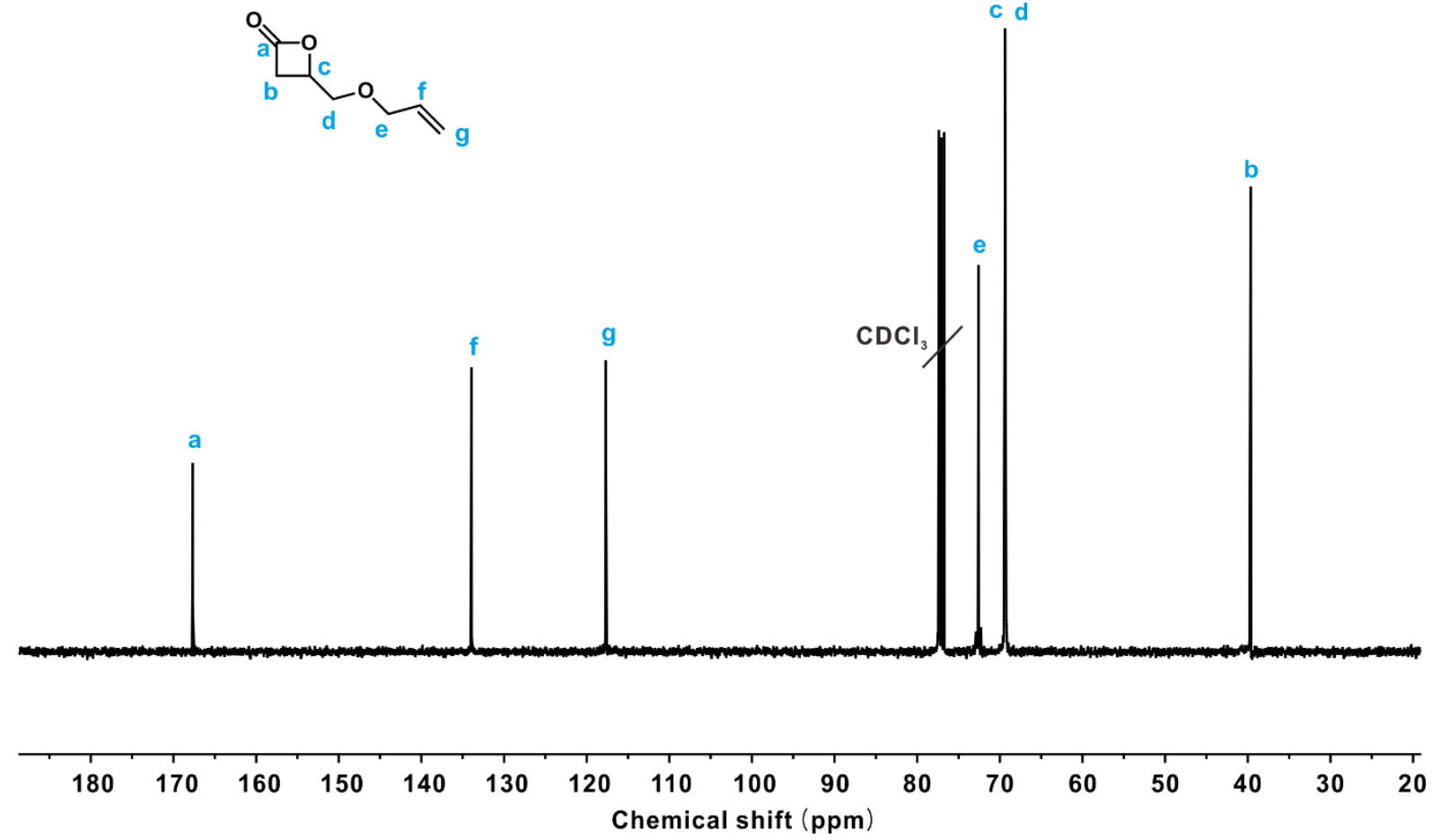

Figure S1. ${ }^{13} \mathrm{C}$ NMR spectrum of AMPL $\left(101 \mathrm{MHz}, \mathrm{CDCl}_{3}\right)$. 


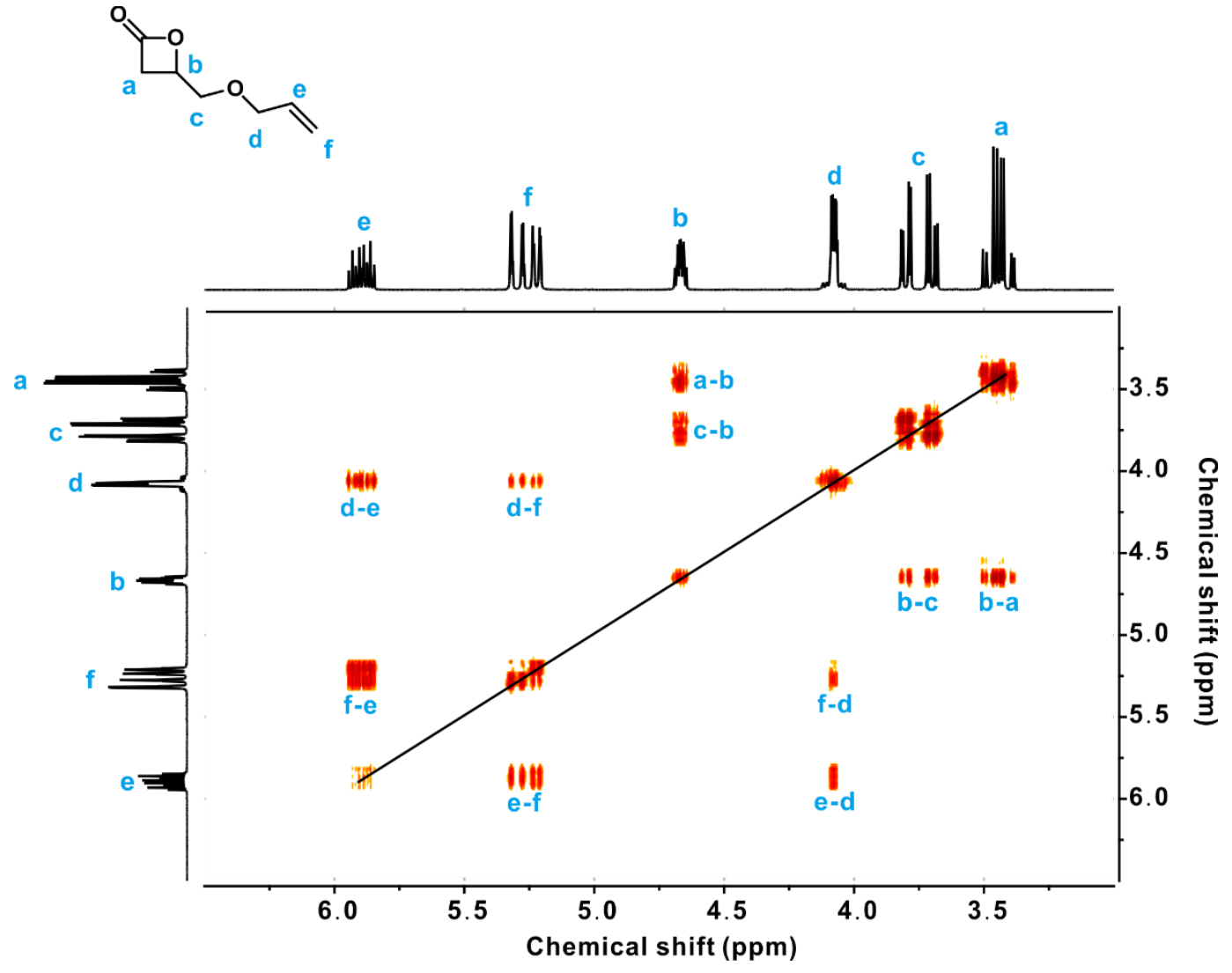

Figure S2. ${ }^{1} \mathrm{H}-{ }^{1} \mathrm{H}$ COSY NMR spectrum of AMPL in $\mathrm{CDCl}_{3}$. 


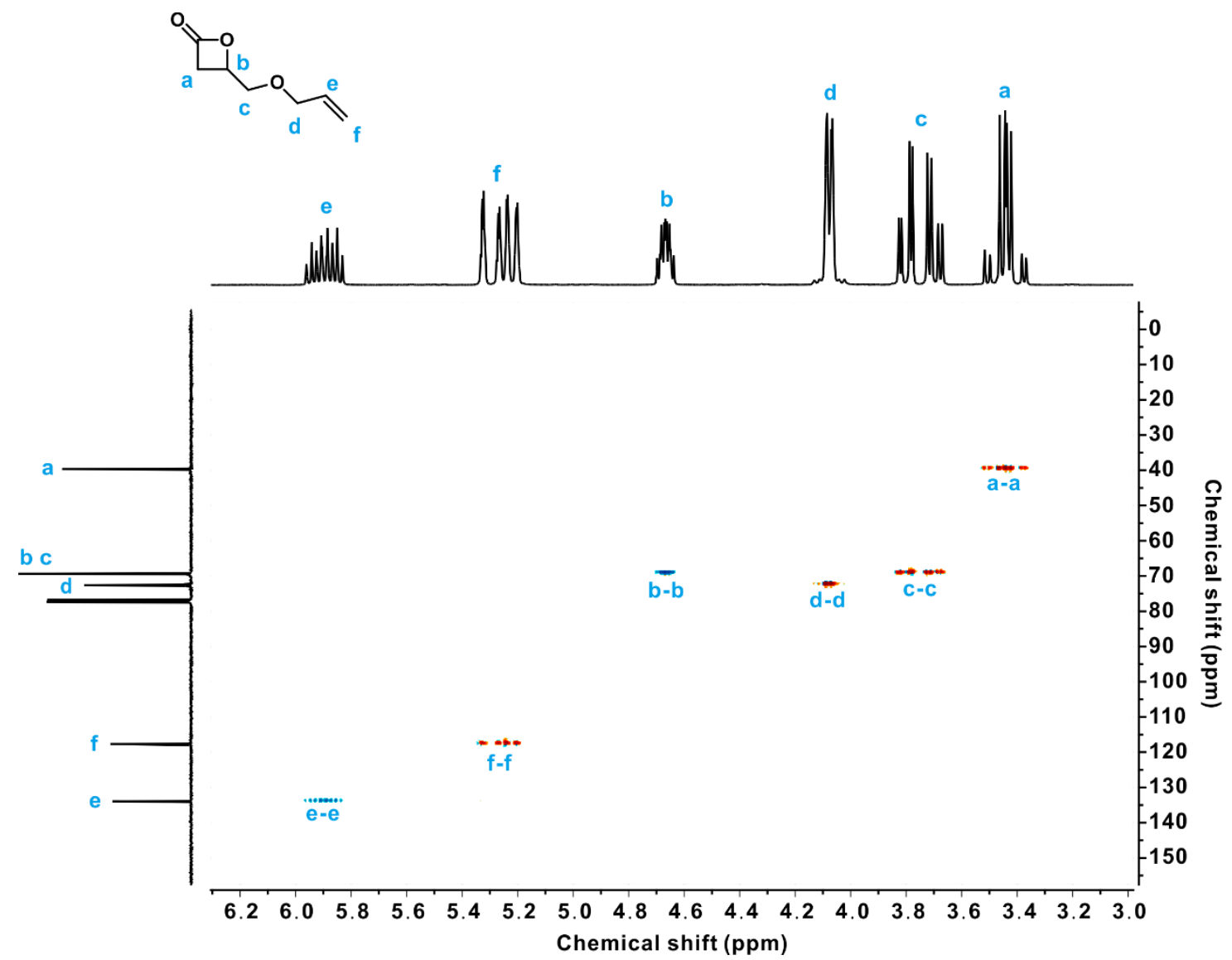

Figure S3. ${ }^{1} \mathrm{H}-{ }^{13} \mathrm{C}$ HSQC NMR spectrum of AMPL in $\mathrm{CDCl}_{3}$. 


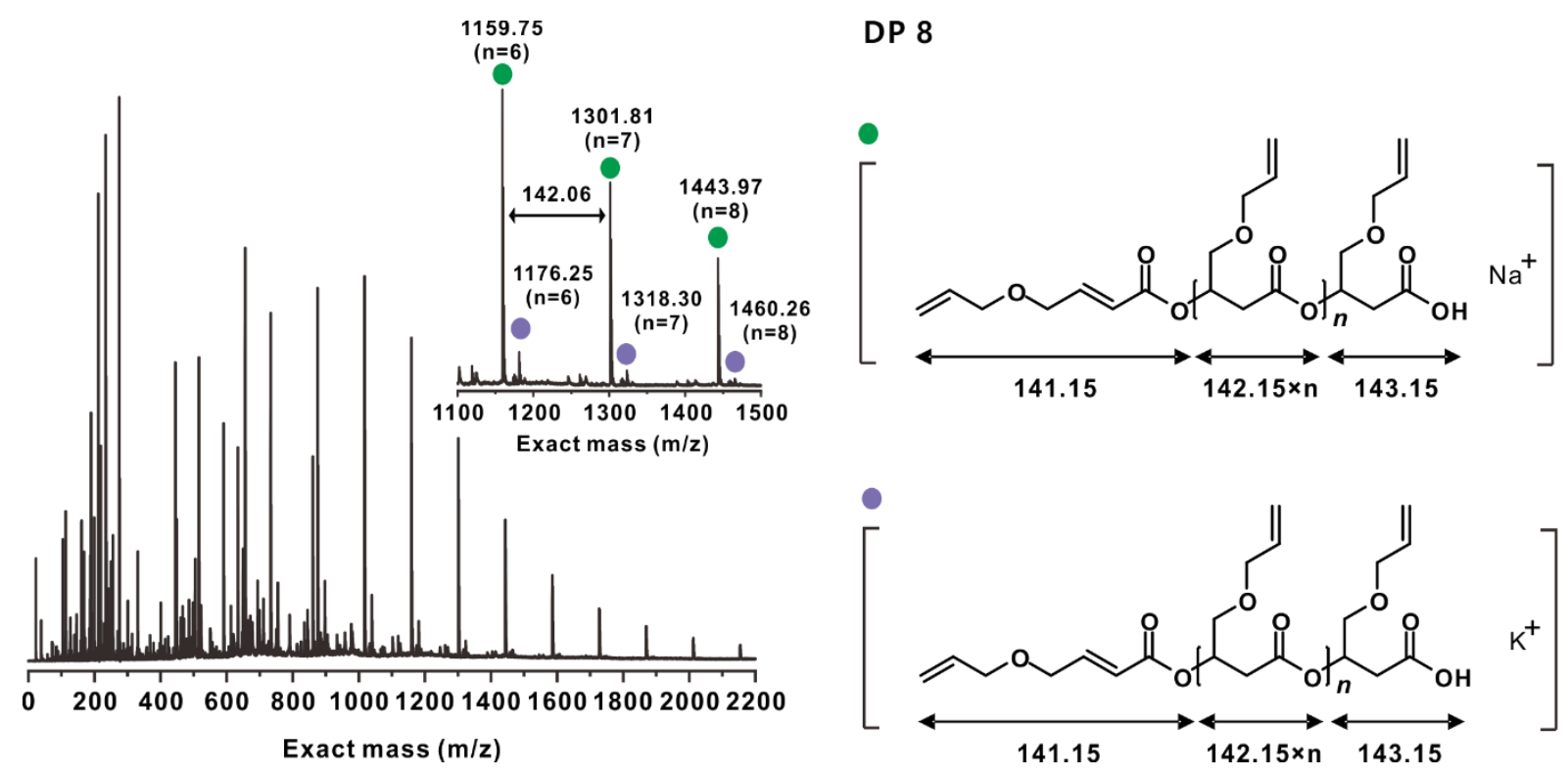

Figure S4. MALDI-ToF/ToF MS spectrum of the isolated PAMPLs synthesized by the AROP of AMPL mediated by BEMP (positive mode, $\mathrm{CHCA}$ matrix, $\mathrm{Na}^{+}$and $\mathrm{K}^{+}$as cationizing salts). 


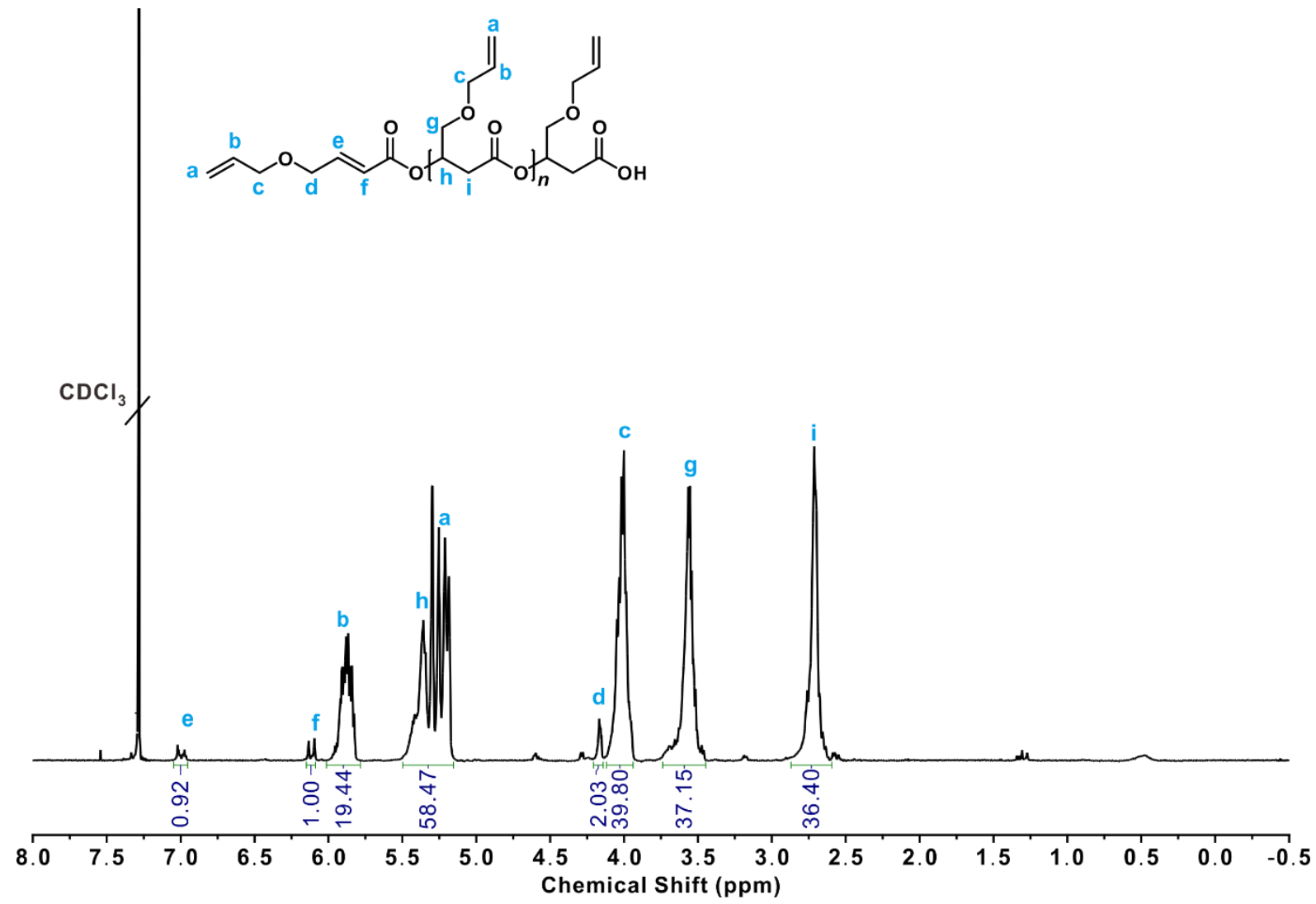

Figure S5. ${ }^{1} \mathrm{H}$ NMR spectrum of PAMPLs synthesized by $t$-BuP 4 (entry 5 in Table 1) (400 $\left.\mathrm{MHz}, \mathrm{CDCl}_{3}\right)$. 


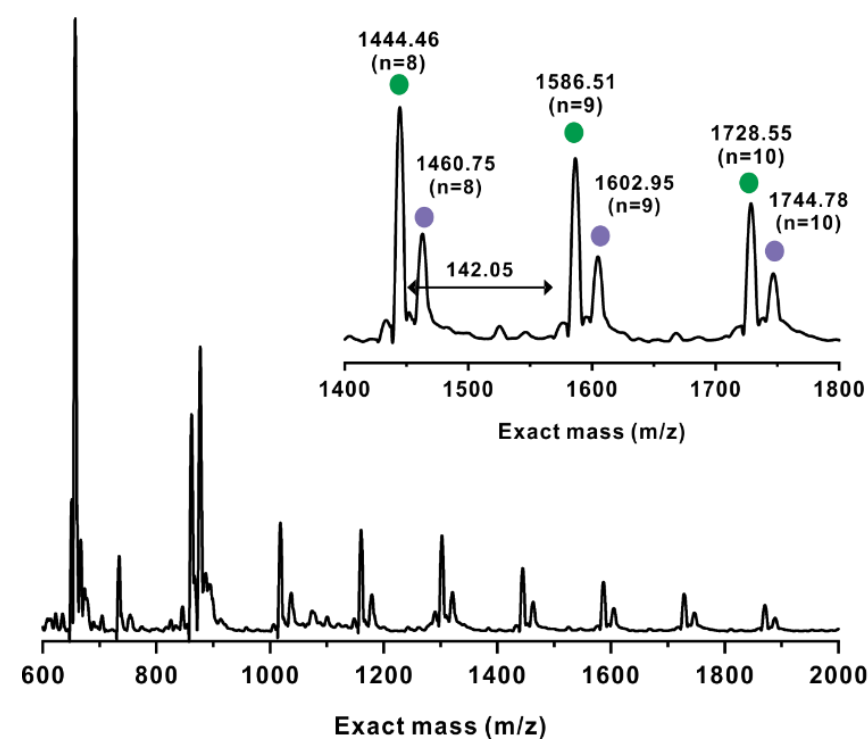

$$
\text { DP } 8
$$
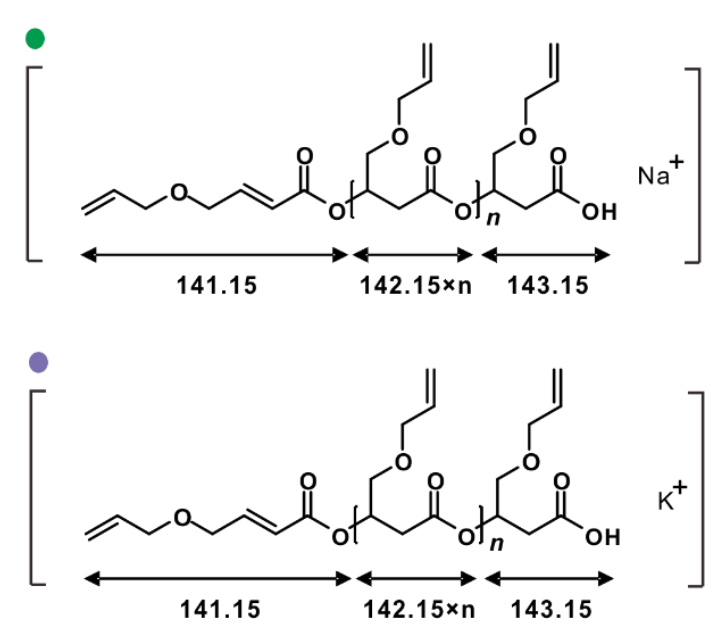

Figure S6. MALDI-ToF/ToF MS spectrum of the isolated PAMPLs synthesized by the AROP of AMPL mediated by $t$-BuP 4 (positive mode, CHCA matrix, $\mathrm{Na}^{+}$and $\mathrm{K}^{+}$as cationizing salts). 

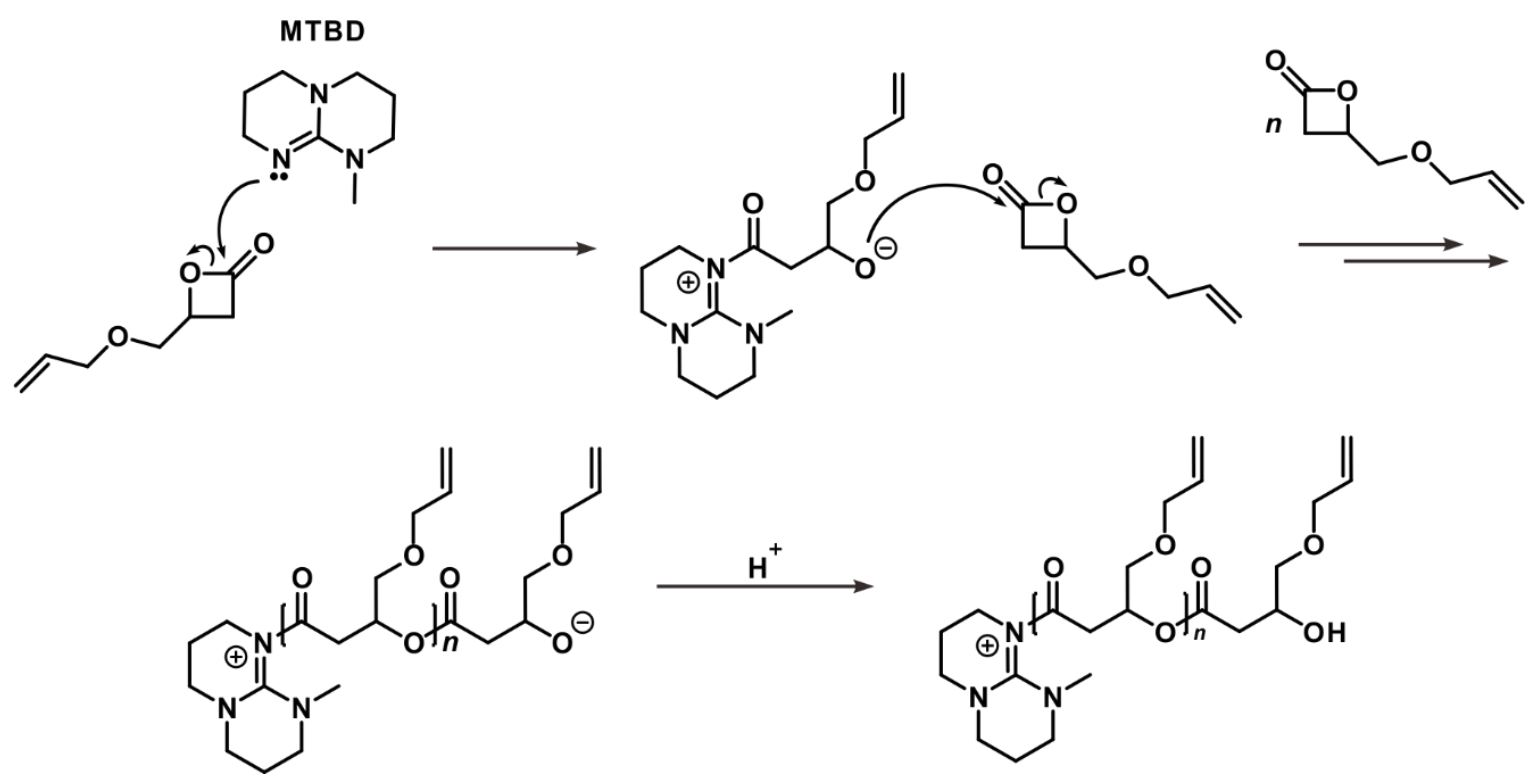

Scheme S1. A proposed mechanism for the anionic ring-opening polymerization of AMPL with MTBD as a nucleophile. MTBD was used as a representative nucleophile. 


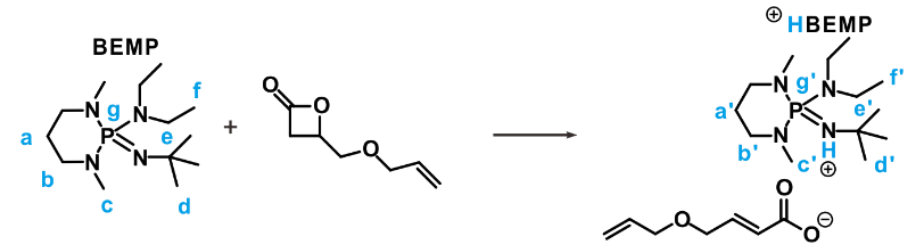

(a)

PAMPL with Conv. $91 \%$ *: Polymer

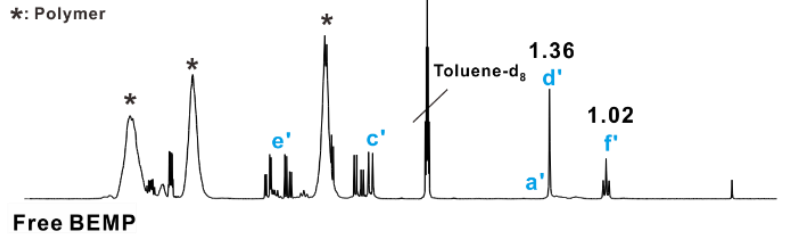

Free BEMP

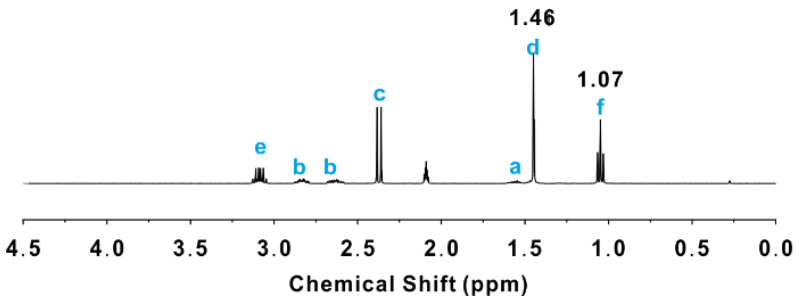

(b)

PAMPL with Conv. $91 \%$
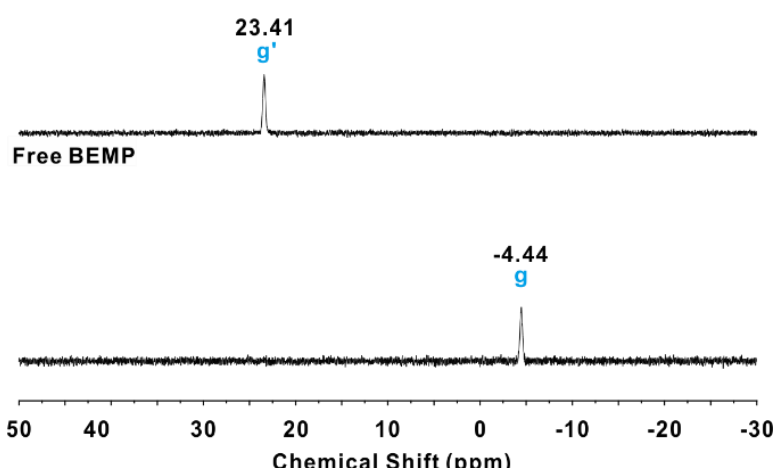

Figure S7. (a) ${ }^{1} \mathrm{H}(400 \mathrm{MHz})$ and (b) ${ }^{31} \mathrm{P}(162 \mathrm{MHz})$ NMR spectra of the ring-opening polymerization of AMPL mediated by BEMP measured in dry toluene- $d_{8}$ to avoid adventitious protonation by $\mathrm{H}_{2} \mathrm{O}$. 


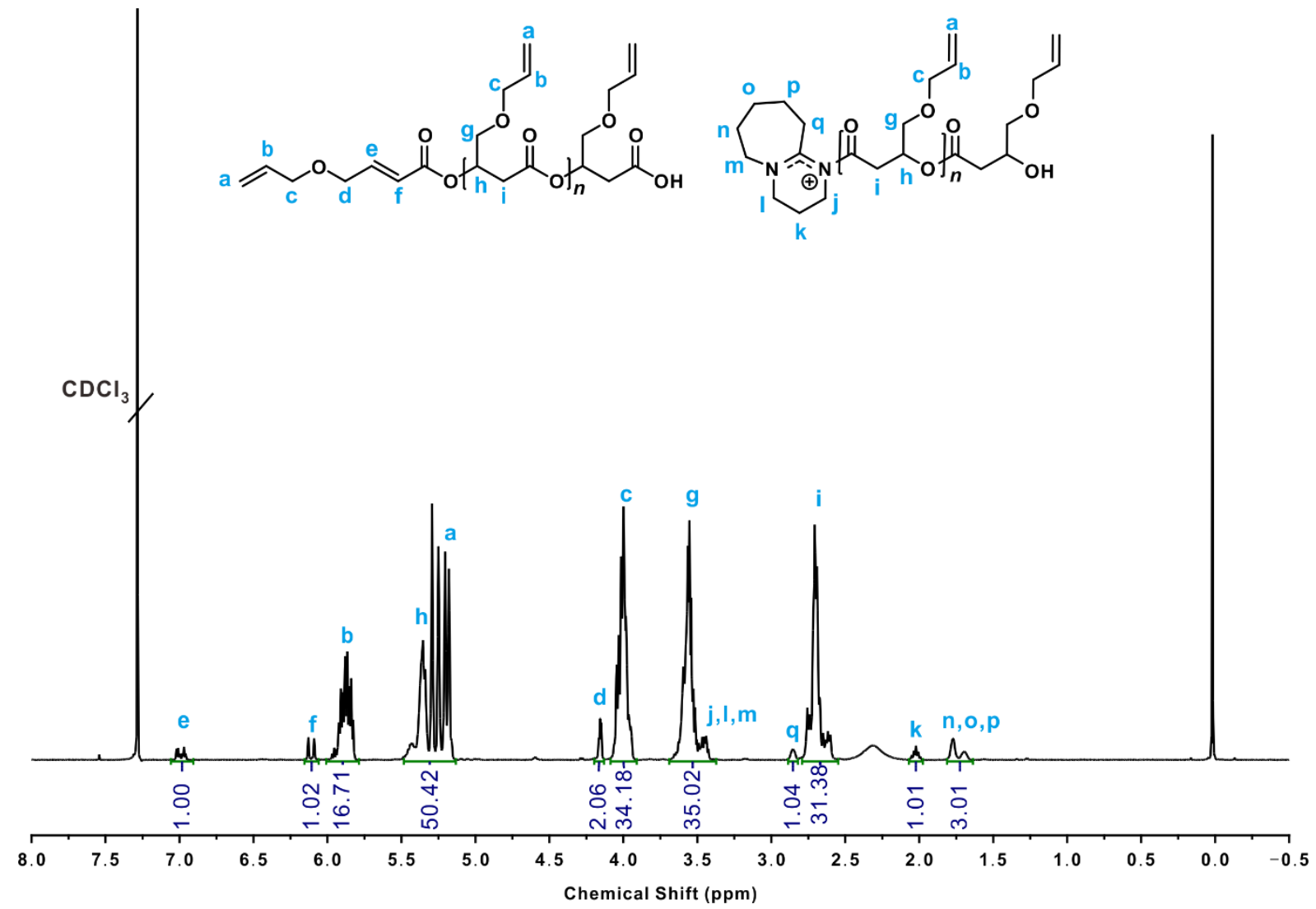

Figure S8. ${ }^{1} \mathrm{H}$ NMR spectrum of PAMPLs synthesized by DBU (entry 6 in Table 1$)(400 \mathrm{MHz}$, $\left.\mathrm{CDCl}_{3}\right)$. 


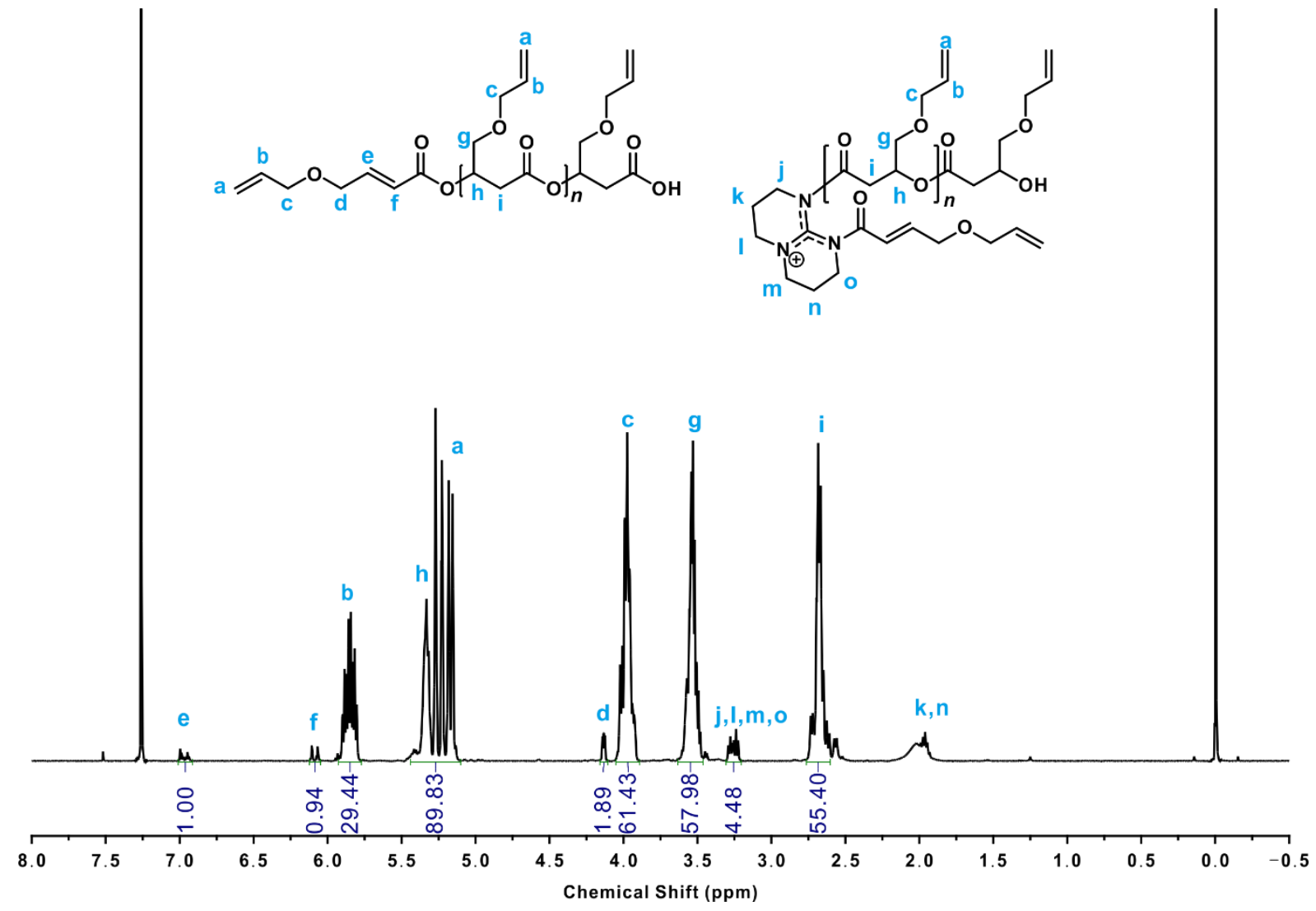

Figure S9. ${ }^{1} \mathrm{H}$ NMR spectrum of PAMPLs synthesized by TBD (entry 7 in Table 1$)(400 \mathrm{MHz}$, $\left.\mathrm{CDCl}_{3}\right)$. 

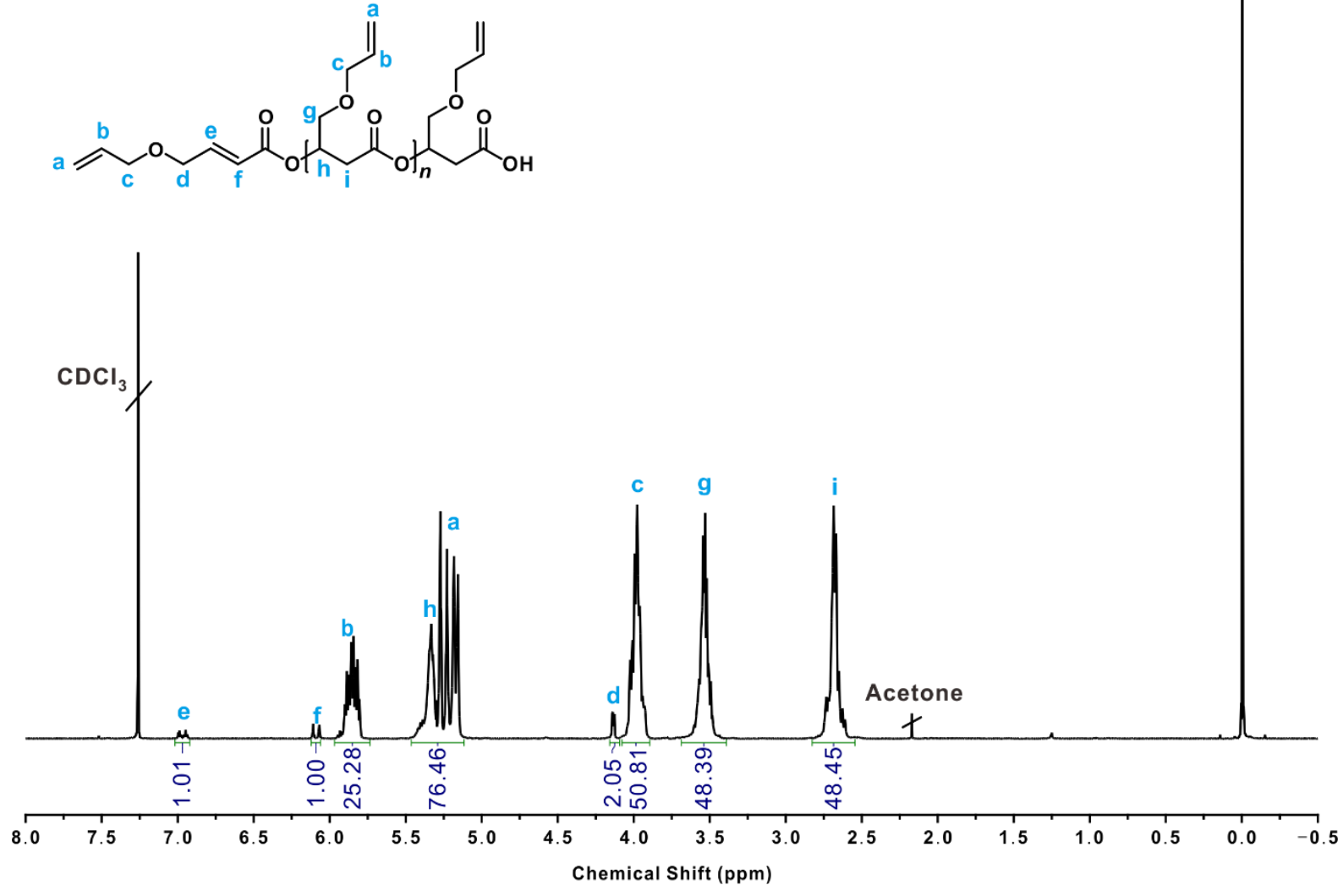

Figure S10. ${ }^{1} \mathrm{H}$ NMR spectrum of PAMPLs synthesized by MTBD (entry 8 in Table 1) (400 $\left.\mathrm{MHz}, \mathrm{CDCl}_{3}\right)$. 


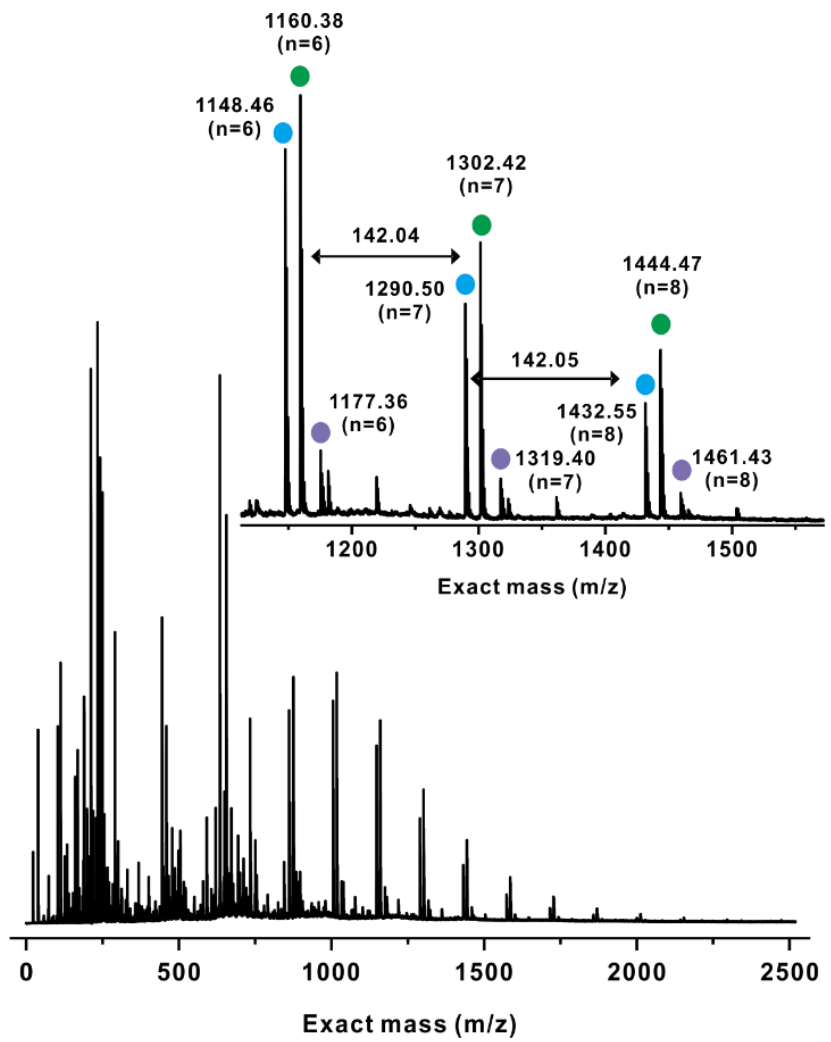

DP 13
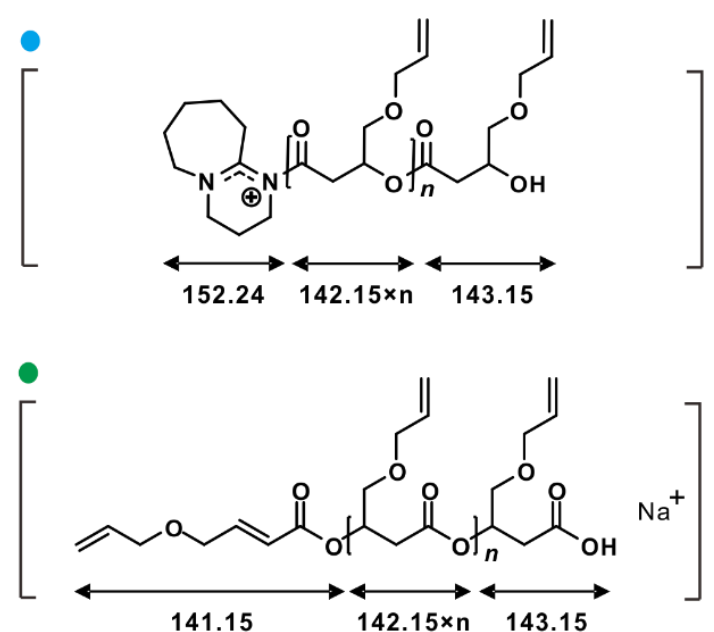

Figure S11. MALDI-ToF/ToF MS spectrum of the isolated PAMPLs synthesized by the AROP of AMPL mediated by DBU (positive mode, $\mathrm{CHCA}$ matrix, $\mathrm{Na}^{+}$and $\mathrm{K}^{+}$as cationizing salts). 

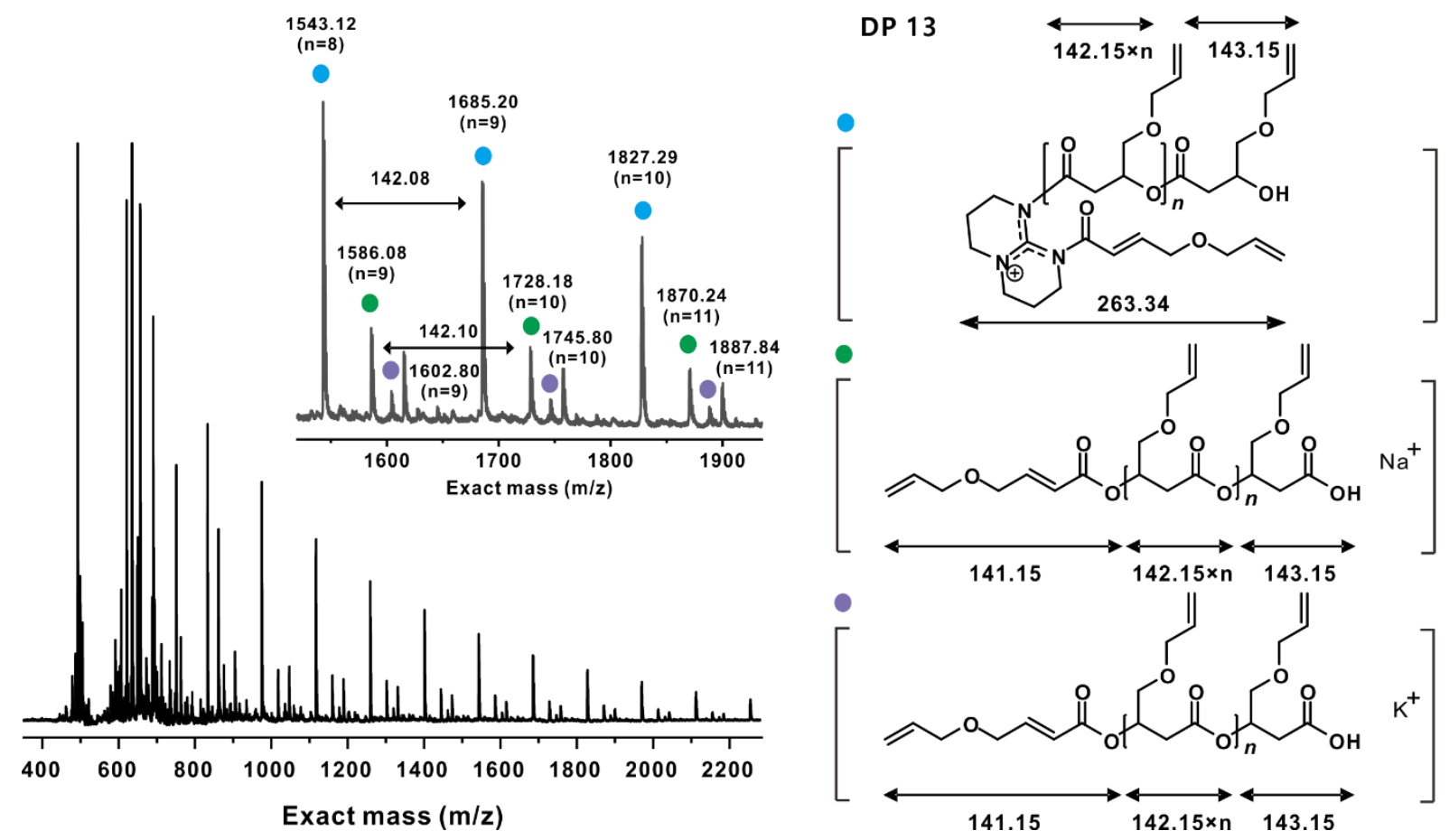

Figure S12. MALDI-ToF/ToF MS spectrum of the isolated PAMPLs synthesized by the AROP of AMPL mediated by TBD (positive mode, CHCA matrix, $\mathrm{Na}^{+}$and $\mathrm{K}^{+}$as cationizing salts). 

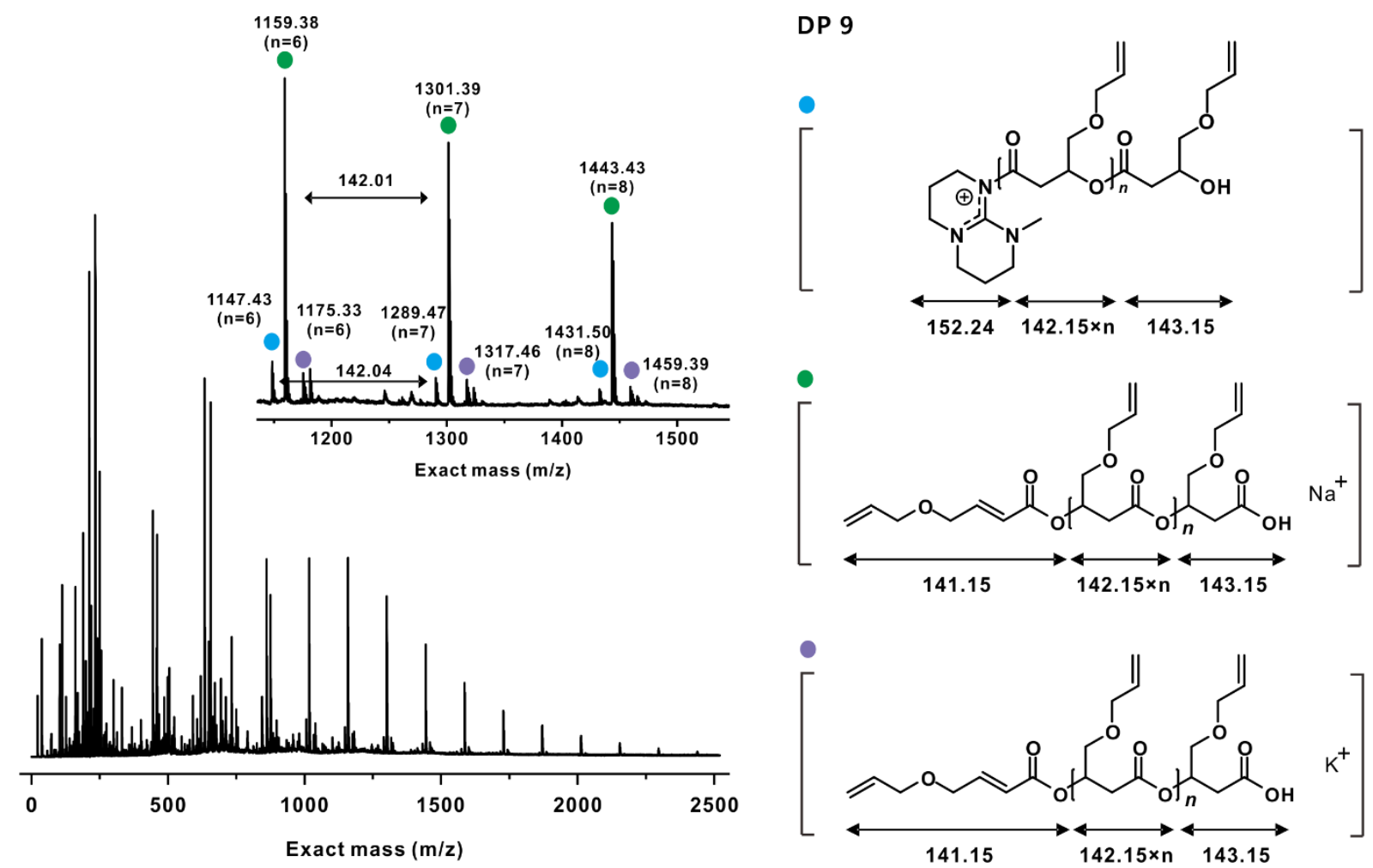

Figure S13. MALDI-ToF/ToF MS spectrum of the isolated PAMPLs synthesized by the AROP of AMPL mediated by MTBD (positive mode, $\mathrm{CHCA}$ matrix, $\mathrm{Na}^{+}$and $\mathrm{K}^{+}$as cationizing salts). 


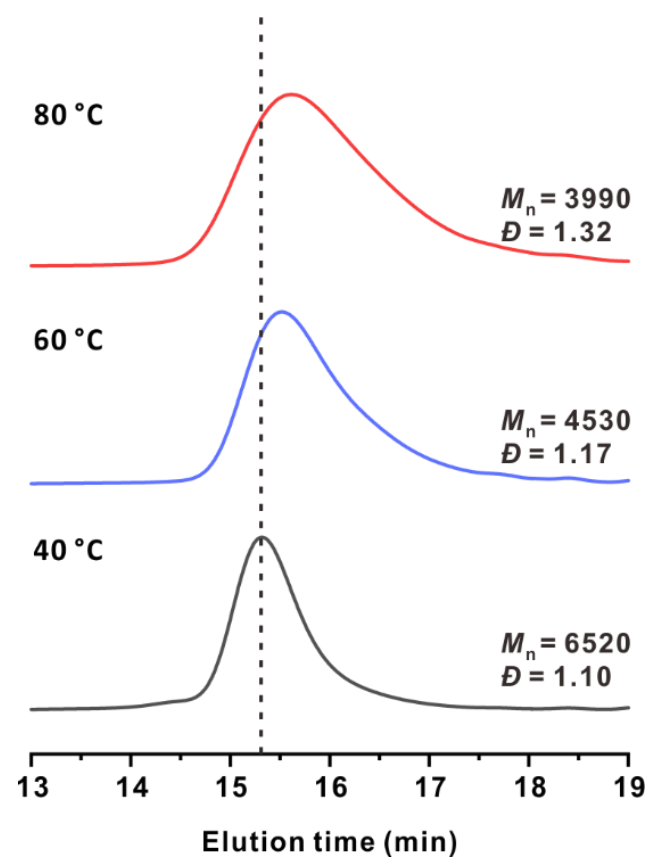

Figure S14. GPC curves of PAMPL with increasing temperature from 40 to $80{ }^{\circ} \mathrm{C}$ with the corresponding number-averaged molecular weight $\left(M_{\mathrm{n}}\right)$ and molecular weight distribution $(\nexists)$ (THF, RI signals, PS standards). 

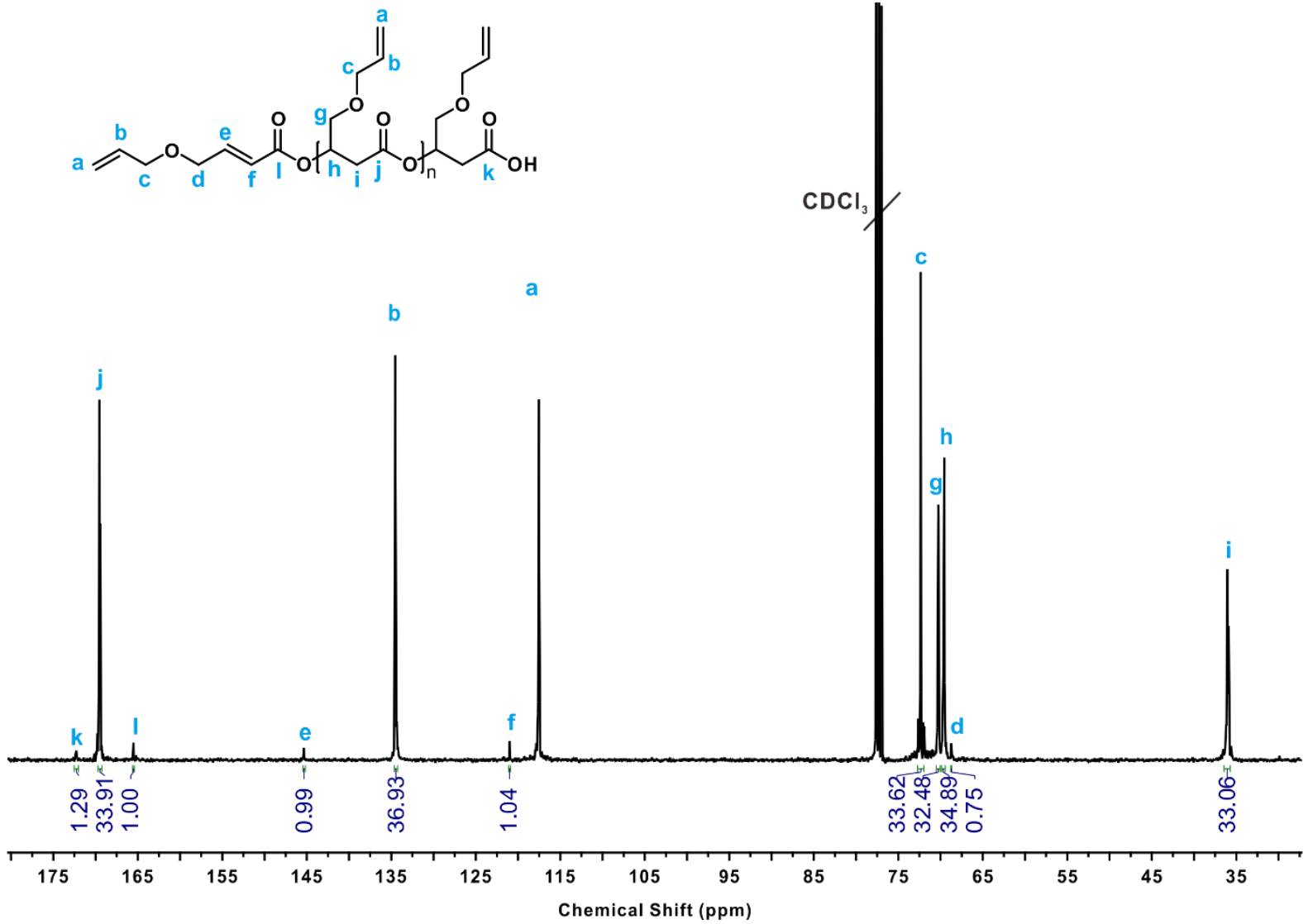

Figure S15. ${ }^{13} \mathrm{C}$ NMR spectrum of PAMPL synthesized by BEMP (entry 2 in Table 1) (101 $\left.\mathrm{MHz}, \mathrm{CDCl}_{3}\right)$. 


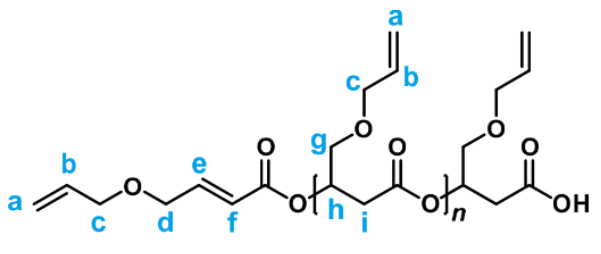

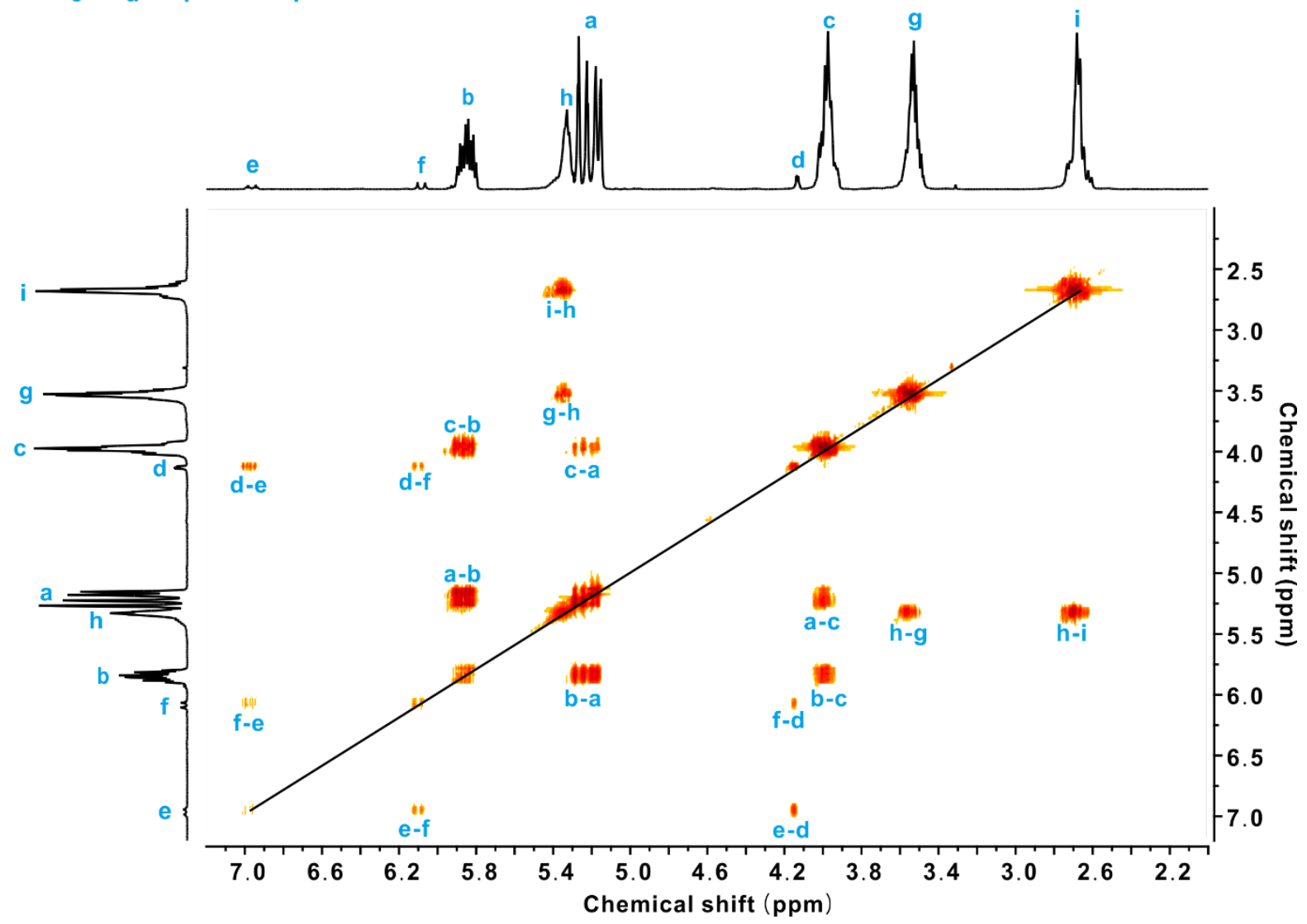

Figure S16. ${ }^{1} \mathrm{H}-{ }^{1} \mathrm{H}$ COSY NMR spectrum of PAMPL mediated by BEMP in $\mathrm{CDCl}_{3}$ (entry 2 in Table 1). 


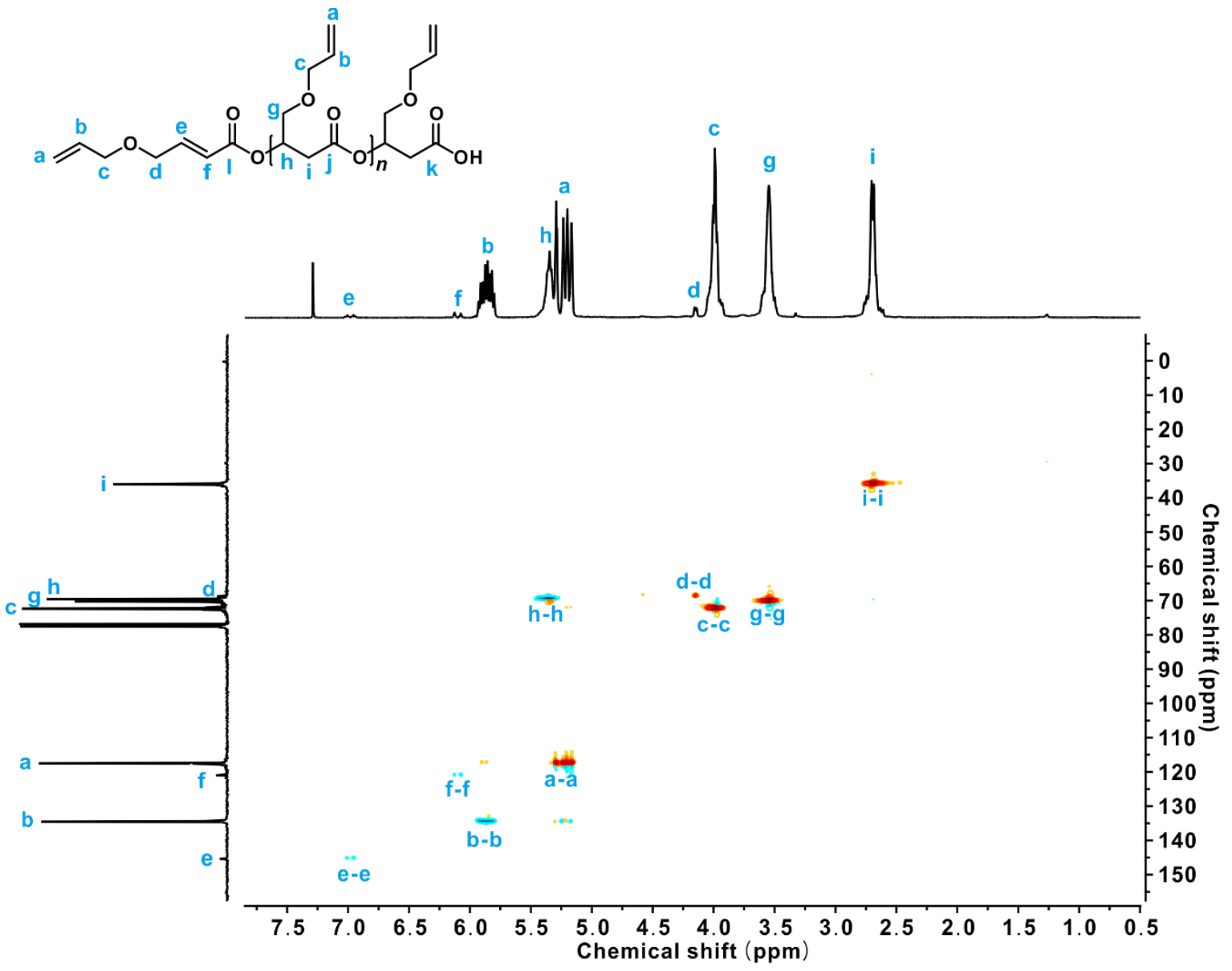

Figure S17. ${ }^{1} \mathrm{H}-{ }^{13} \mathrm{C}$ HSQC NMR spectrum of PAMPL mediated by BEMP in $\mathrm{CDCl}_{3}$ (entry 2 in Table 1). 


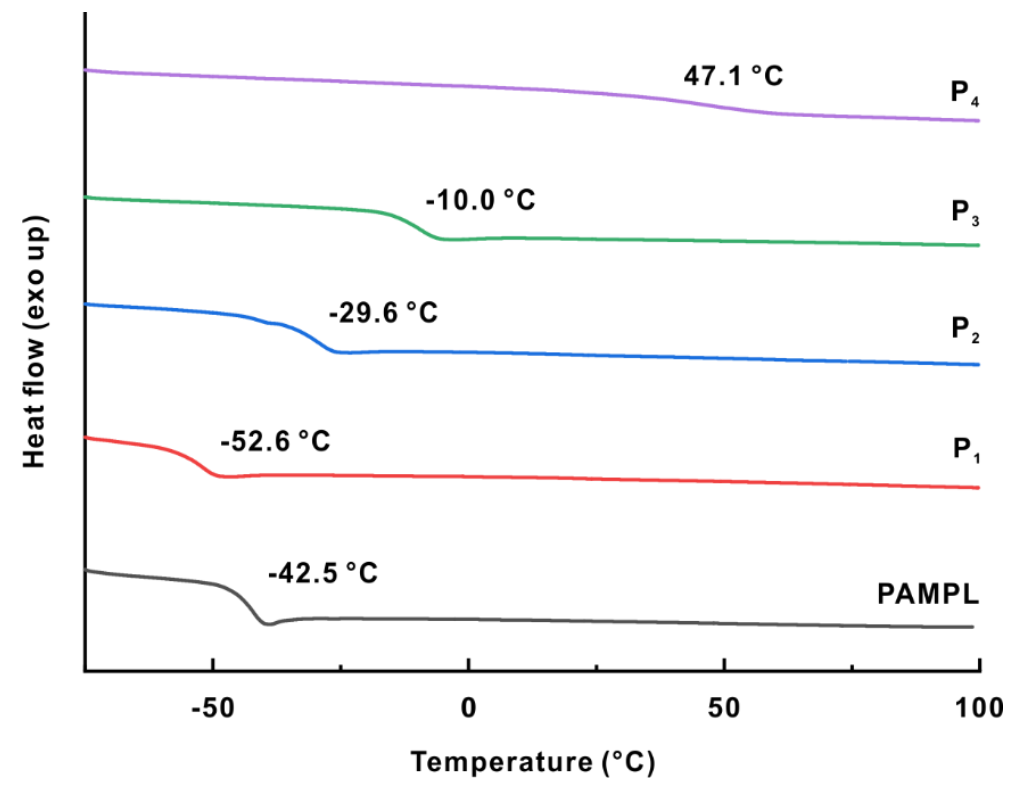

Figure S18. DSC thermograms of the PAMPL polymer after PPM via the thiol-ene reaction with the corresponding thiol-molecules, yielding $\mathrm{P}_{1}-\mathrm{P}_{4}$ polymers. 


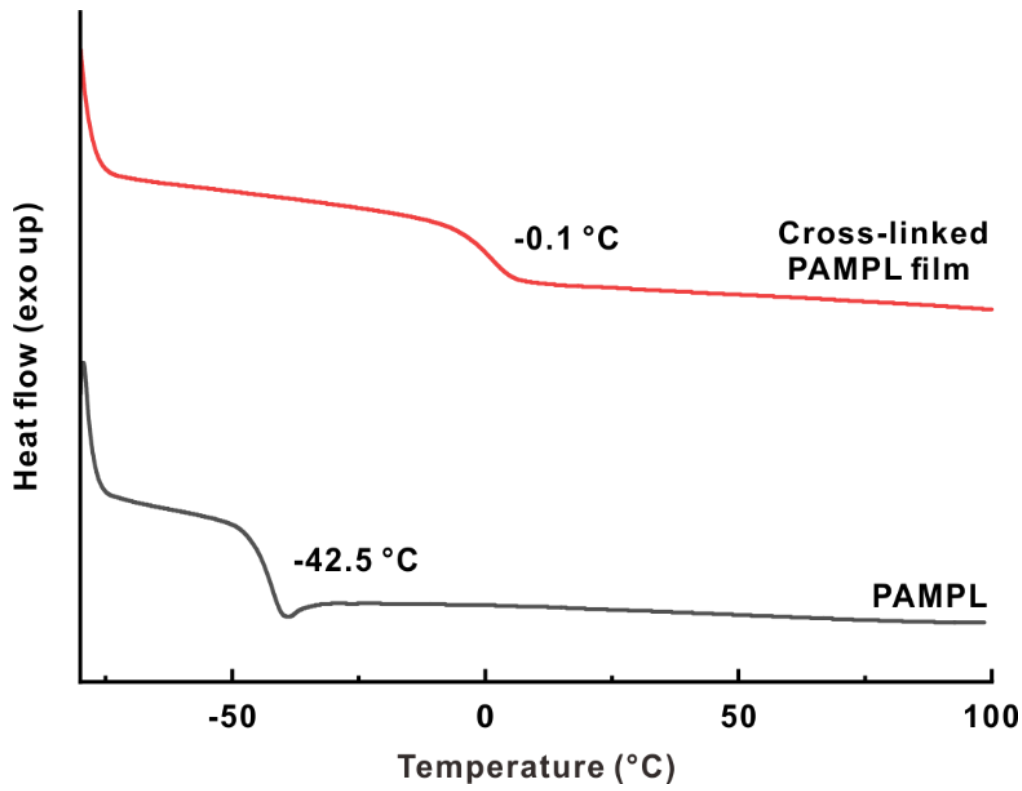

Figure S19. DSC thermograms of the cross-linked PAMPL film after PPM via the thiol-ene reaction with PETMP crosslinker. 


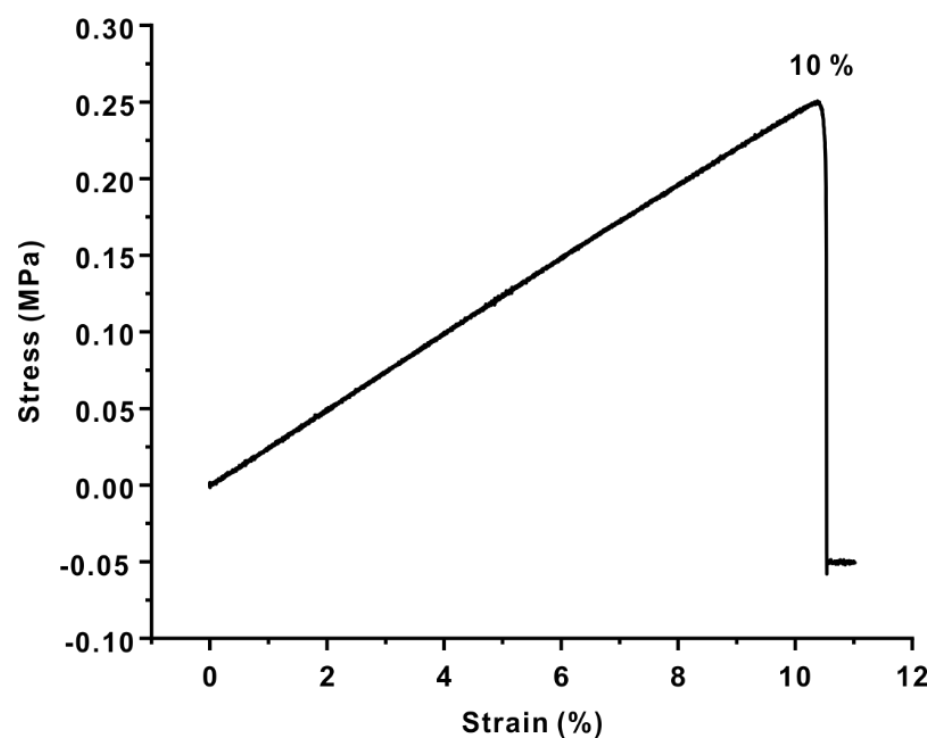

Figure S20. Tensile stress-strain curves of the cross-linked PAMPL films prepared by cutting the films in the shape of a dumbbell $\left(24 \times 16 \times 0.50 \mathrm{~mm}^{3}\right)$. The crosshead speed was $1 \mathrm{~mm}$ $\min ^{-1}$. 


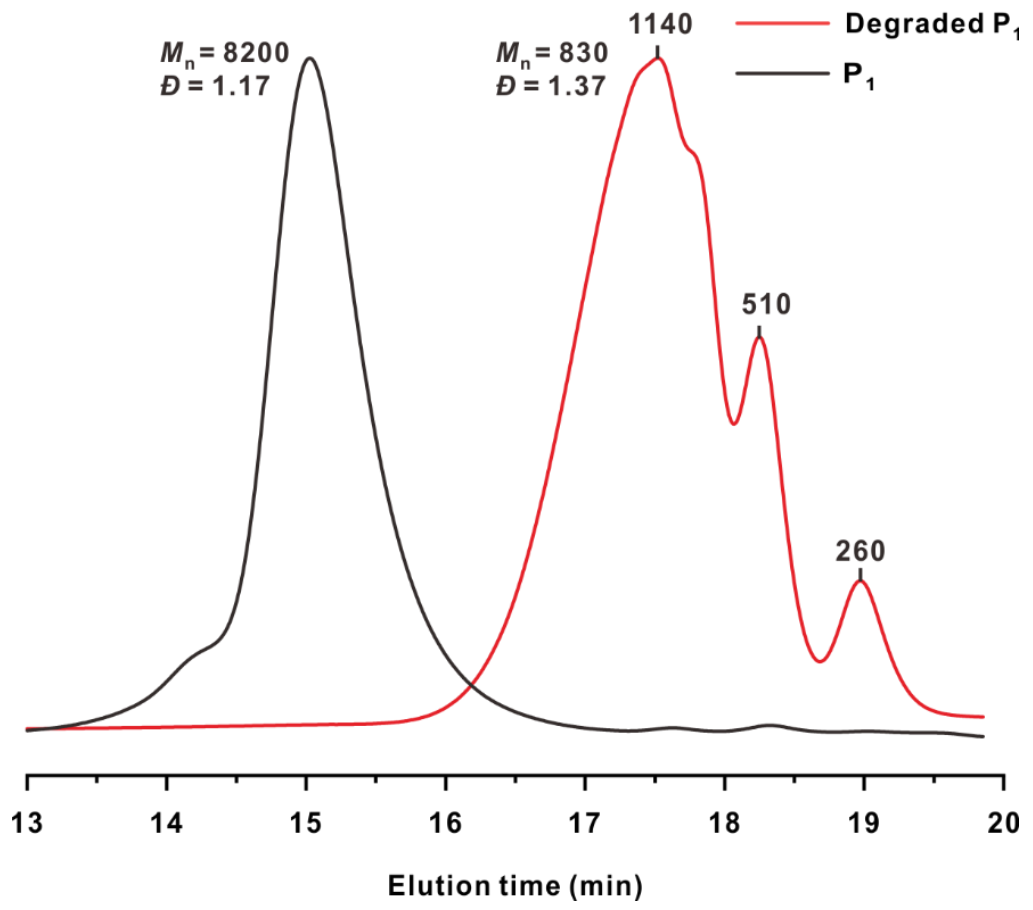

Figure S21. GPC curves of (black) $\mathrm{P}_{1}$ and (red) $\mathrm{P}_{1}$ degraded by BEMP for $1 \mathrm{~h}$ (THF, RI signals, PS standards). 


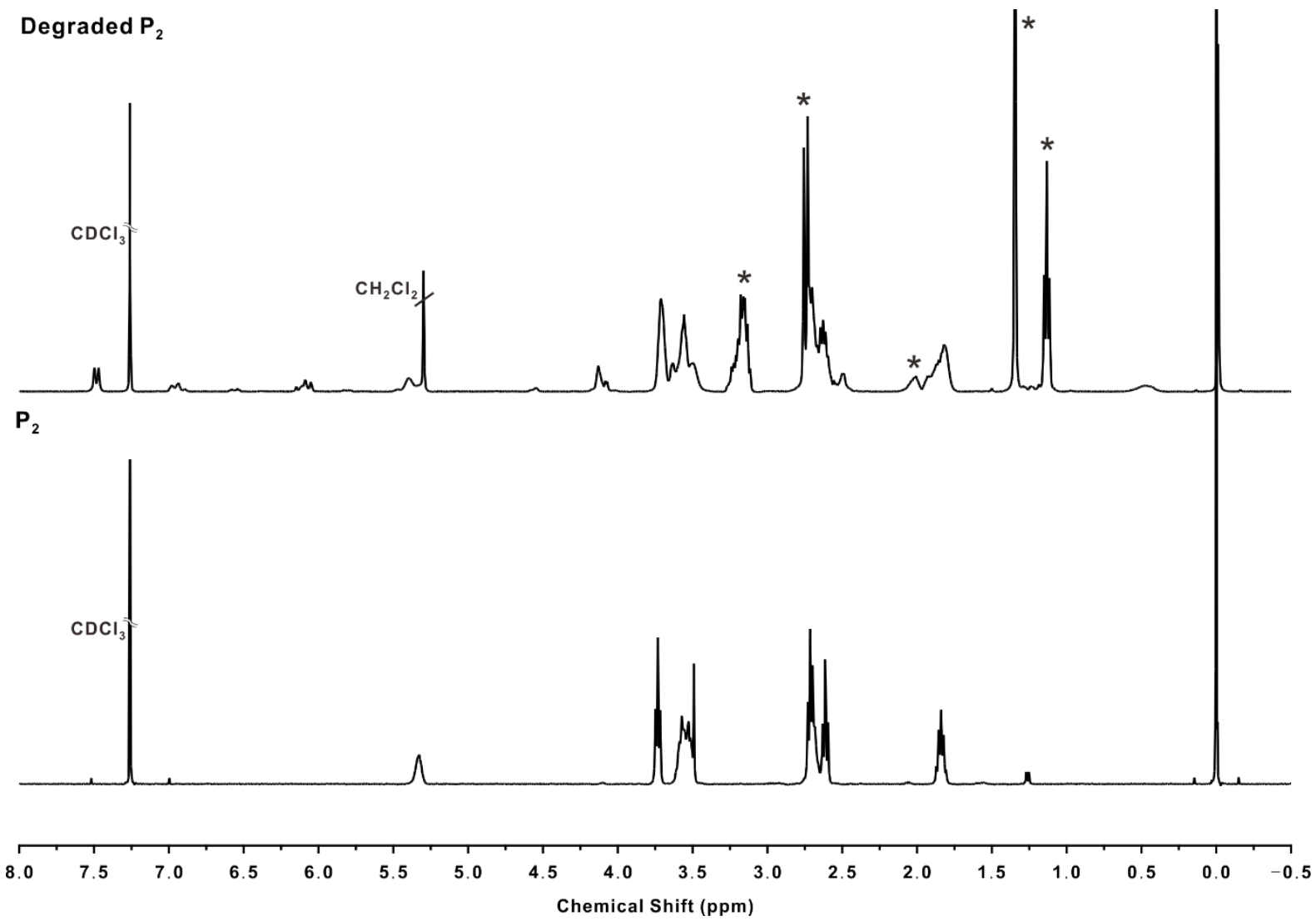

Figure S22. ${ }^{1} \mathrm{H}$ NMR spectra of $\mathrm{P}_{2}$ and degraded $\mathrm{P}_{2}$ by BEMP for $1 \mathrm{~h}\left(400 \mathrm{MHz}, \mathrm{CDCl}_{3}\right)$. Peaks with asterisks $(*)$ indicate the residual BEMP during the degradation. 


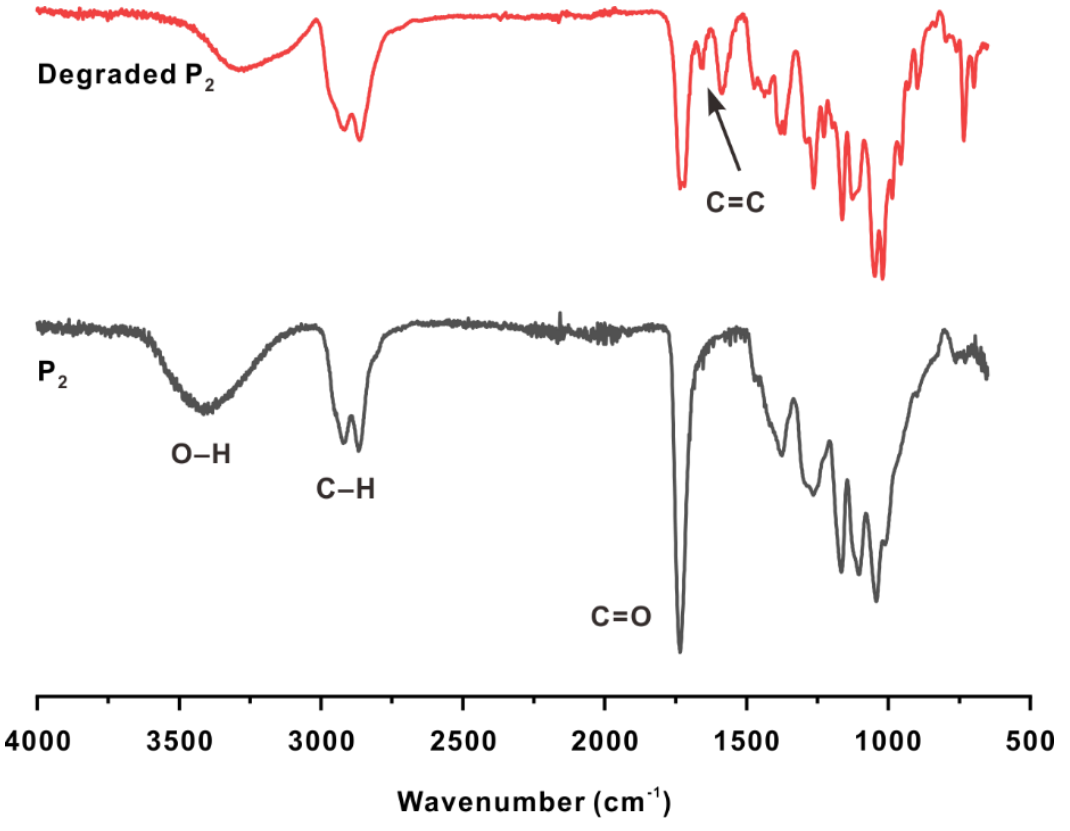

Figure S23. FT-IR spectra of (black) $\mathrm{P}_{2}$ and (red) $\mathrm{P}_{2}$ degraded by BEMP for $1 \mathrm{~h}$. 


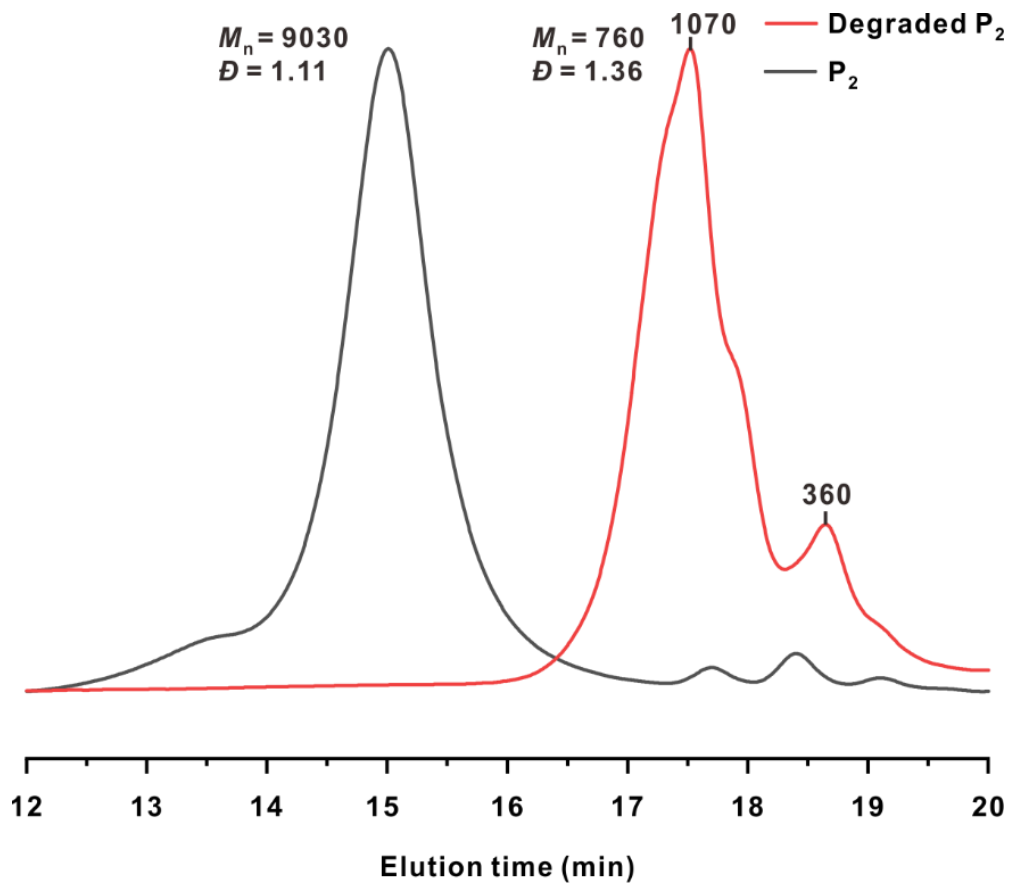

Figure S24. GPC curves of (black) $\mathrm{P}_{2}$ and (red) $\mathrm{P}_{2}$ chemically degraded by BEMP for $1 \mathrm{~h}$ (THF, RI signals, PS standards). 
(a)
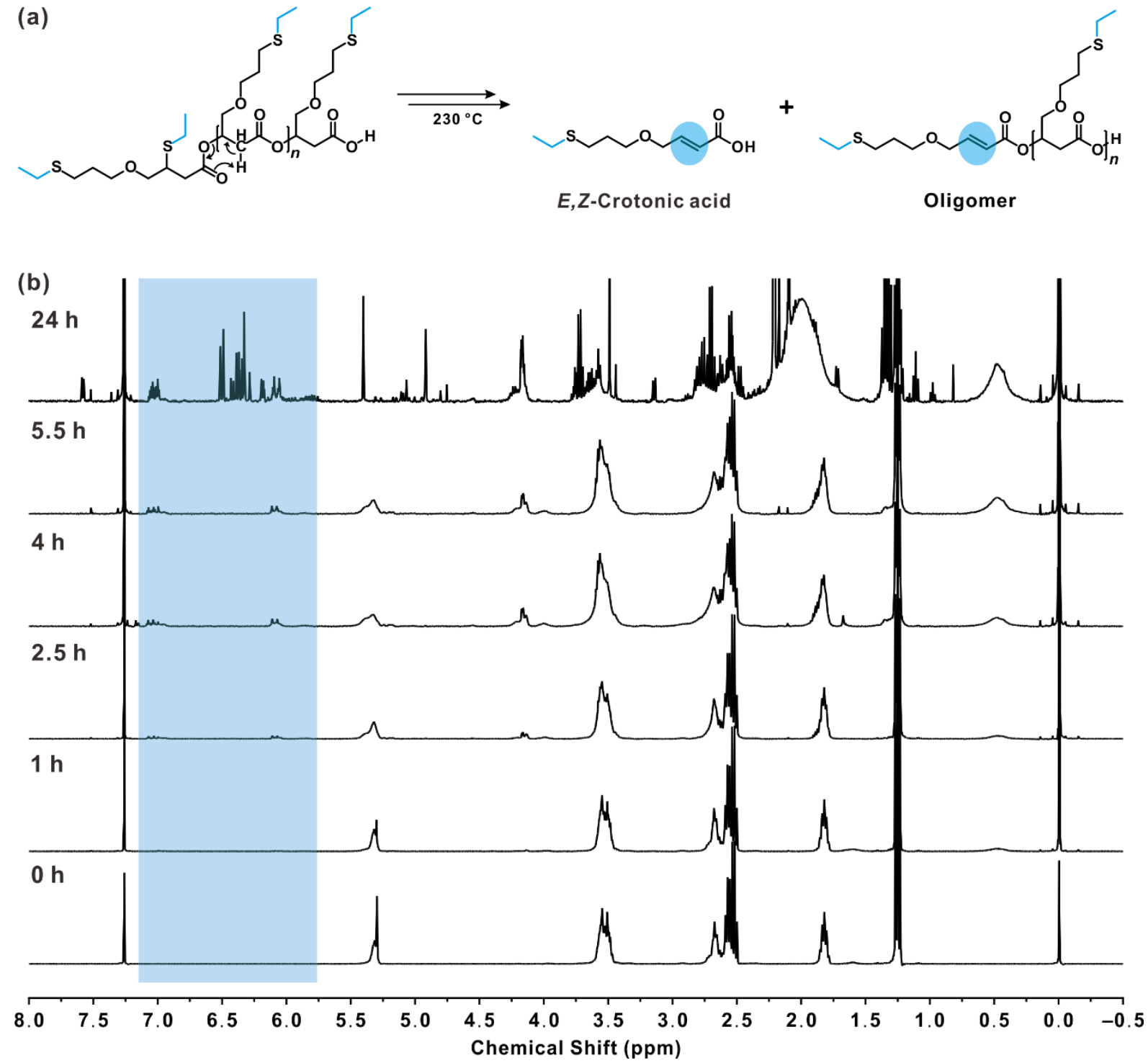

Figure S25. Thermal degradation of $\mathrm{P}_{1}$ at $230{ }^{\circ} \mathrm{C}$. (a) Degradation mechanism with the corresponding (b) ${ }^{1} \mathrm{H}$ NMR spectra of $\mathrm{P}_{1}$ and thermally degraded $\mathrm{P}_{1}$ over time $(400 \mathrm{MHz}$, $\left.\mathrm{CDCl}_{3}\right)$. 

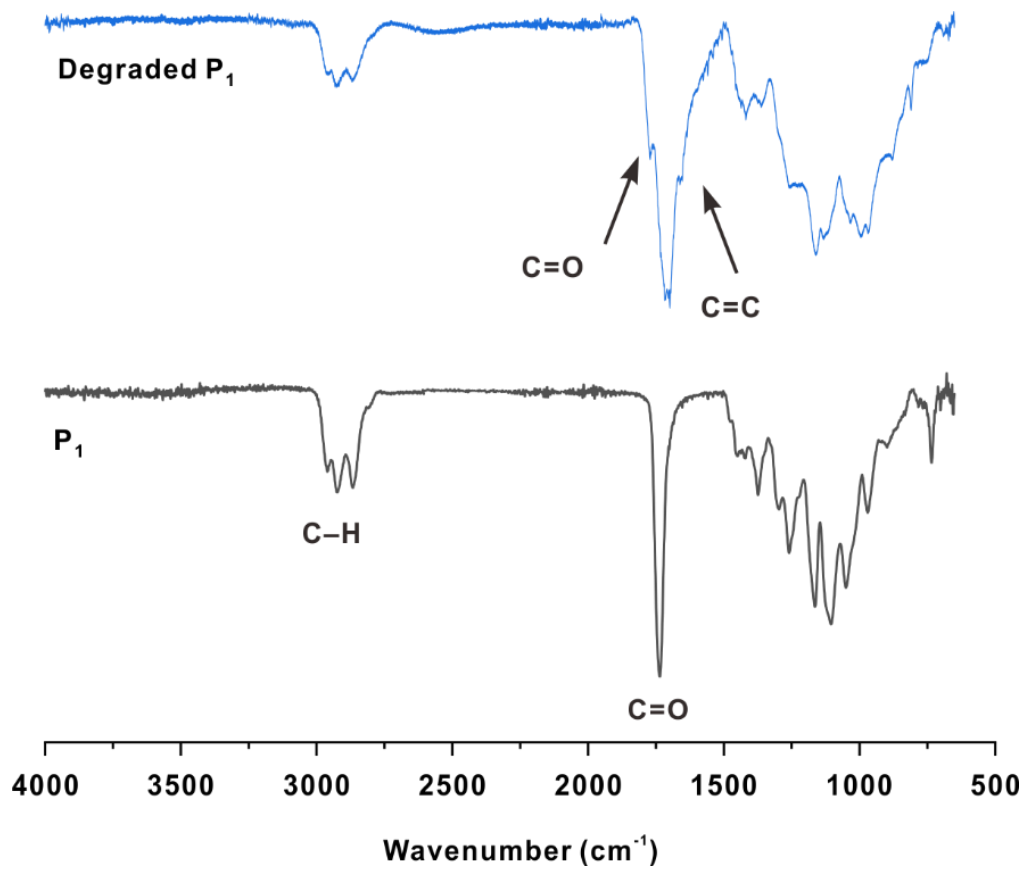

Figure S26. FT-IR spectra of (black) $\mathrm{P}_{1}$ and (blue) thermally degraded $\mathrm{P}_{1}$ for $24 \mathrm{~h}$. 


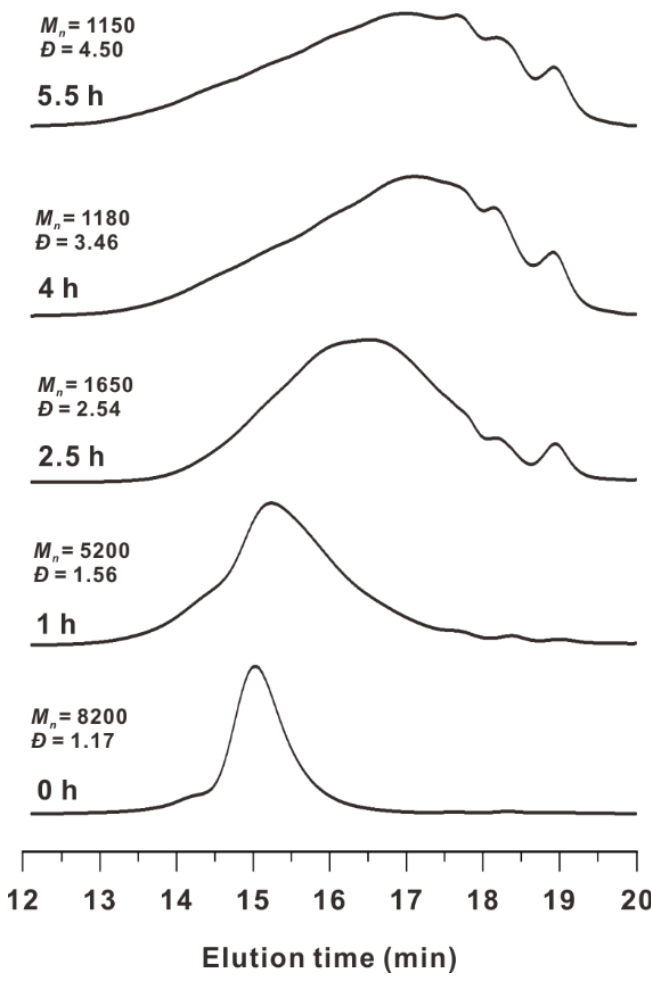

Figure S27. A collection of GPC curves for the thermal degradation of $\mathrm{P}_{1}$ with respect to time with the corresponding number-averaged molecular weight $\left(M_{\mathrm{n}}\right)$ and distribution $(\bigoplus)(\mathrm{THF}, \mathrm{RI}$ signals, PS standards). 


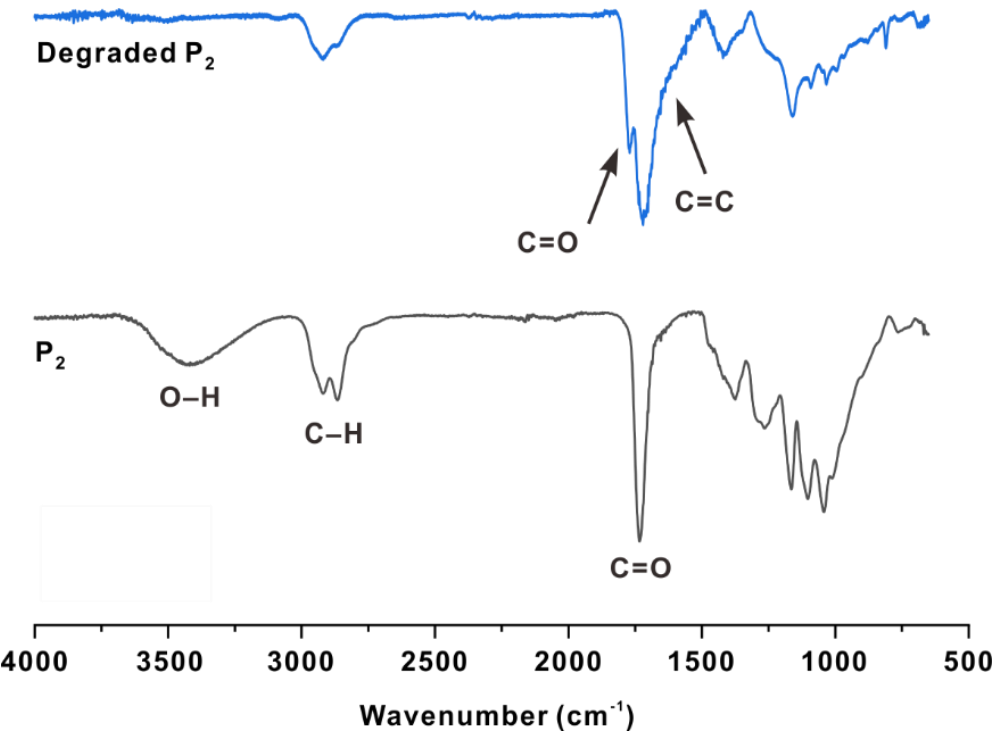

Figure S28. FT-IR spectra of (black) $\mathrm{P}_{2}$ and (blue) thermally degraded $\mathrm{P}_{2}$ for $24 \mathrm{~h}$. 


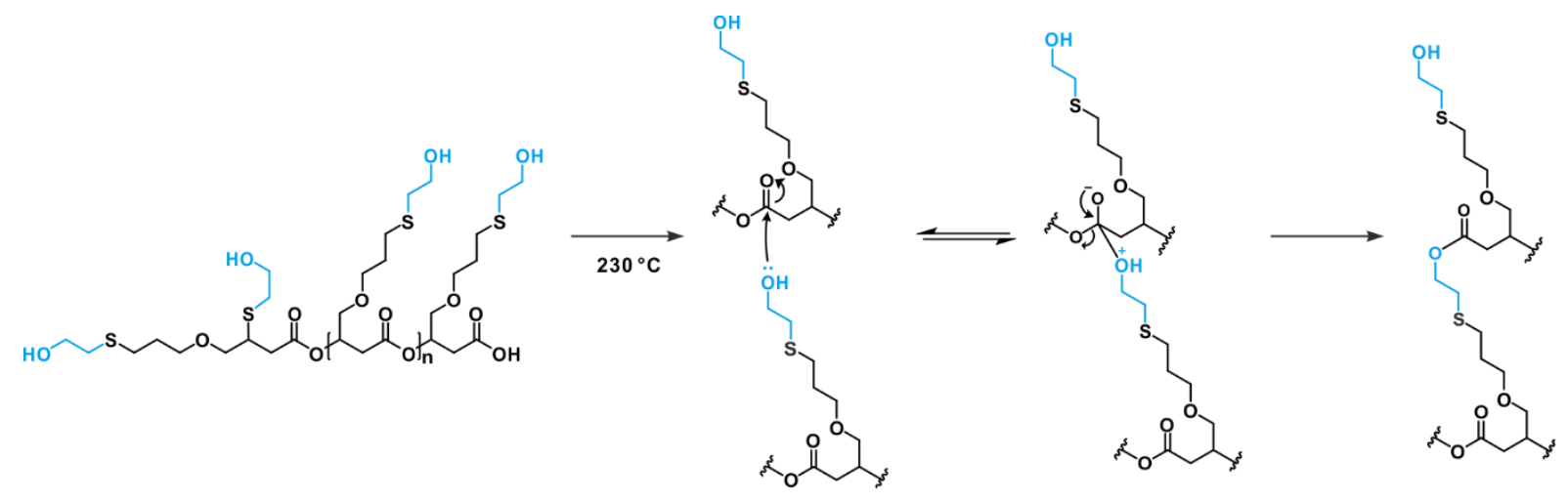

Figure S29. Representative thermal degradation mechanism of $\mathrm{P}_{2}$ proceeding via transesterification. 
(a)

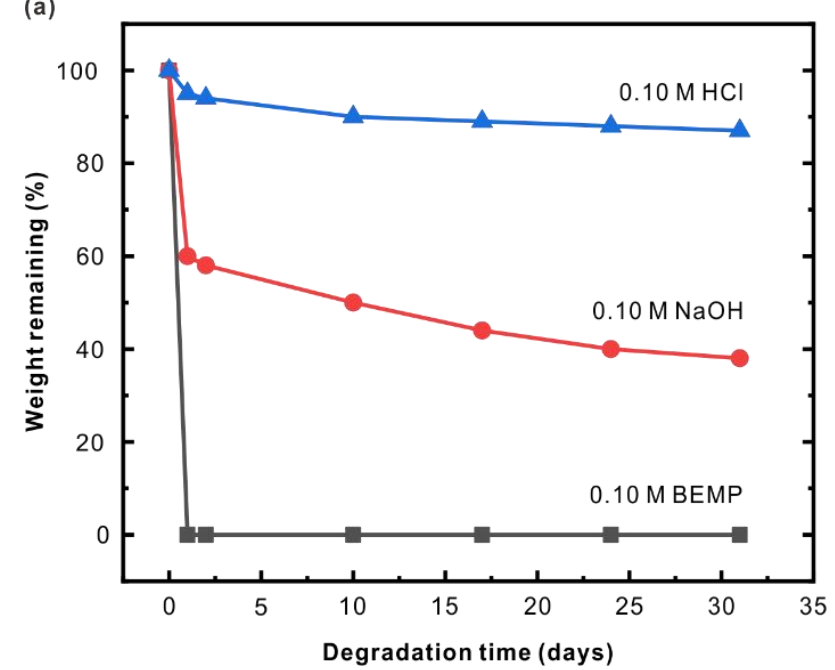

(b)

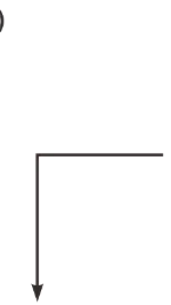

$0.10 \mathrm{M}$ BEMP

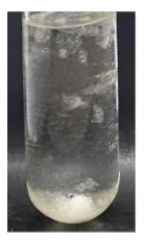

$1 \mathrm{~min}$
PAMPL film

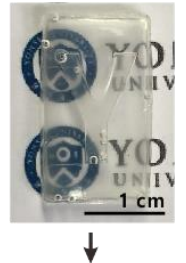

$0.10 \mathrm{M} \mathrm{NaOH}$

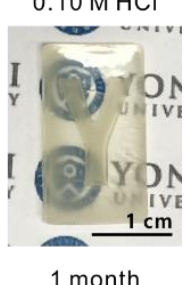

Figure S30. Degradability of the cross-linked PAMPL film. (a) Time-dependent weight loss of cross-linked PAMPL films and (b) photographic images of degraded cross-linked PAMPL films in various conditions (0.10 M BEMP in DCM, $0.10 \mathrm{M} \mathrm{NaOH}$ and $0.10 \mathrm{M} \mathrm{HCl})$. 